\title{
A recente expansão do crédito, o aumento dos preços das commodities, as políticas monetárias dos EUA versus Brasil e a atual pressão inflacionária no regime de metas para a inflação
}

\author{
Luciano Luiz Manarin D’Agostini*
}

RESUMO - Diante do cenário de pressão inflacionária no Brasil, o texto mostra porque existe persistência inflacionária para os próximos períodos, ou seja, porque o IPCA, mesmo com as medidas "macroprudenciais" tomadas pelo governo brasileiro nos últimos meses pode continuar subindo e se aproximar perigosamente do limite superior da meta para a inflação. Em especial, apontam-se quatro motivos para a existência da pressão inflacionária no Brasil, tanto do lado da oferta, quanto do lado da demanda: (i) o aumento dos preços das commodities no mercado futuro; (ii) o alto nível de emprego na economia brasileira verificada nos últimos meses (recorde no regime de metas de inflação); (iii) a recente expansão do crédito no Brasil e; (iv) o programa Quantitative Easing 2 dos Estados Unidos.

Palavras-chave: Política monetária. Instrumentos de controle monetário. Crédito. Inflação.

\section{INTRODUÇÃO}

O Índice de Preços ao Consumidor Amplo (IPCA) subiu 0,80\% em fevereiro, ante alta de 0,83\% em janeiro. Em 12 meses, o IPCA acumula alta de 6,01\% a.a., seguindo ainda num patamar elevado. É o maior índice acumulado desde novembro de 2008 (Gráfico 1) e também é o sétimo aumento seguido.

GRÁFICO 1 - IPCA MENSAL ACUMULADO EM 12 MESES E META PARA INFLAÇÃO - 2000-2011

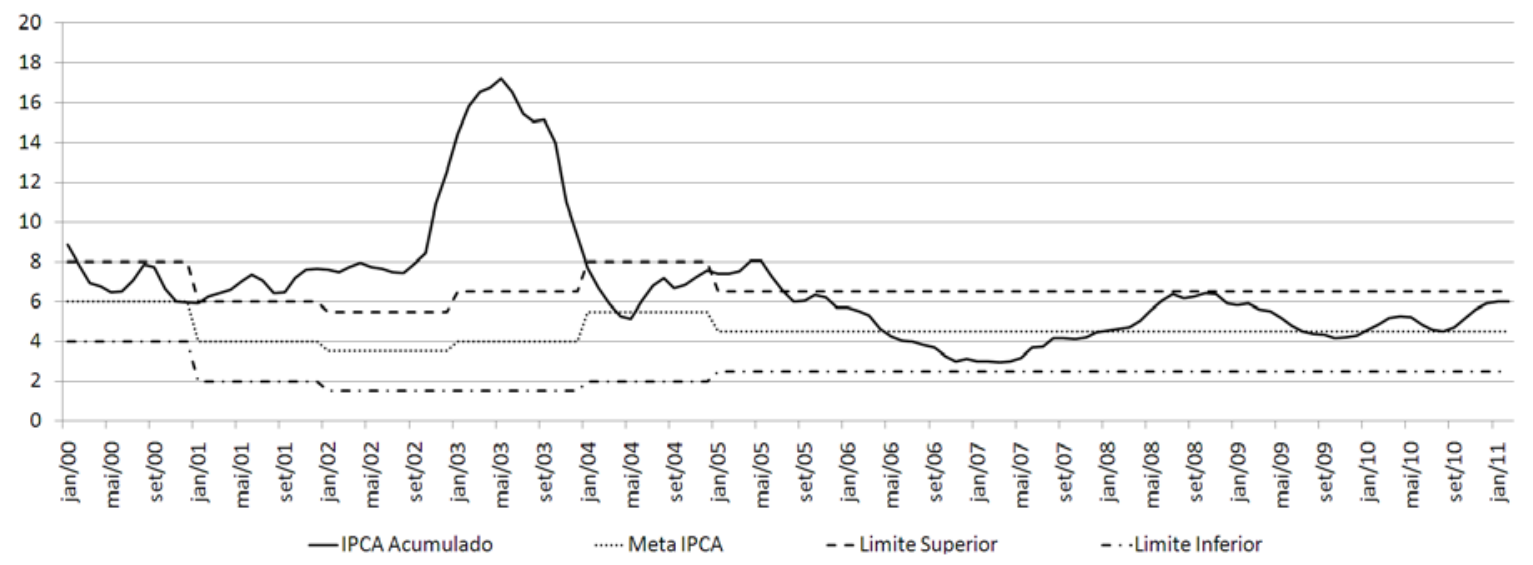

FONTE: Banco Central do Brasil.

\footnotetext{
* Doutor em desenvolvimento econômico pela Universidade Federal do Paraná e pesquisador de métodos de previsões em política monetária. É Professor dos Programas de Pós-Graduação em Finanças do IBPEX/UNINTER e FACSUL. Endereço eletrônico: lucianodagostini@yahoo.com.br.
} 
No boletim Focus do Banco Central do Brasil (BCB), analistas previam uma expectativa acumulada do IPCA em 12 meses de 6,06\%. Assim, o IPCA acumulado, divulgado pelo IBGE, veio levemente abaixo das expectativas do mercado financeiro e, portanto, sem grandes surpresas. O que ocorre é que persiste o cenário de aumento da inflação, mesmo com as medidas "macroprudenciais" tomadas pelo governo brasileiro nos últimos meses. Em especial, dentro do regime de metas de inflação, com a meta definida em 4,5\% a.a. para 2011, com um limite superior de 6,5\% a.a., verifica-se que o IPCA aproxima-se perigosamente do teto superior da meta de inflação.

Na política monetária, uma questão pertinente e preocupante no atual debate brasileiro refere-se à elevação observada nos índices de inflação. Nesse sentido, tanto do lado da oferta quanto do lado da demanda, quatro fatores sustentaram nestes últimos meses, e ainda poderão sustentar nos próximos períodos, a elevação da inflação: (1) o aumento sincronizado dos preços das commodities agrícolas e minerais nos diversos mercados futuros mundiais; (2) o alto nível de emprego na economia brasileira verificada nos últimos meses (recorde no regime de metas de inflação), deixando a economia mais aquecida, (3) a recente expansão do crédito no Brasil; (4) o resultado do excesso de liquidez criado pelo Banco Central dos Estados Unidos, por intermédio do Quantitative Easing 2 (EQ2), que mantém uma taxa de juros próxima de zero, desde meados de 2008, exportando inflação para o Brasil e para os demais países emergentes.

\section{O AUMENTO DOS PREÇOS DAS COMMODITIES AGRÍCOLAS E MINERAIS NO MERCADO FUTURO}

Em 12 meses, de janeiro de 2010 a janeiro de 2011 (Tabela 1), observa-se expressiva valorização das commodities agrícolas e minerais no mercado futuro. Como, no geral, os preços das commodities agrícolas e minerais são cotados a preços de mercado internacional, o efeito do aumento dos preços desses produtos, reflete também em efeitos inflacionários nas economias mundiais, contagiando aqui no Brasil, por exemplo, alguns indicadores de preços como o IPCA.

TABELA 1 - VALORIZAÇÃO DAS COMMODITIES E PARTICIPAÇÃO NA PAUTA DE EXPORTAÇÕES BRASILEIRAS

\begin{tabular}{l|r|r}
\hline \multicolumn{1}{c|}{ Produtos } & Participação da Pauta de Exportações & Valorização no Mercado Futuro \\
\hline Minério de Ferro & $16,7 \%$ & $144,8 \%$ \\
Petróleo & $7,8 \%$ & $21 \%$ \\
Açúcar & $4,8 \%$ & $30,9 \%$ \\
Café em Grão & $3,7 \%$ & $40,7 \%$ \\
Carne de Frango & $3,6 \%$ & $17,8 \%$ \\
Celulose & $2,6 \%$ & $12,5 \%$ \\
Farelo de Soja & $2,6 \%$ & $1,3 \%$ \\
\hline
\end{tabular}


TABELA 1 (CONTINUAÇÃO) - VALORIZAÇÃO DAS COMMODITIES E PARTICIPAÇÃO NA PAUTA DE EXPORTAÇÕES BRASILEIRAS

\begin{tabular}{l|r|r}
\multicolumn{1}{c|}{ Produtos } & Participação na Pauta de Exportações & \multicolumn{1}{c}{ Valorização no Mercado Futuro } \\
\hline Carne Bovina & $1,8 \%$ & $30,7 \%$ \\
Soja em Grãos & $0,7 \%$ & $5,6 \%$ \\
\hline
\end{tabular}

FONTE: MDIC e Tendências Consultoria.

A pauta de exportação brasileira concentra 44,3\% em 2 produtos minerais e 7 produtos agrícolas. Como grande exportador de commodities, a balança comercial brasileira acabou se beneficiando claramente com o aumento de preços. Porém uma bolha de preços em commodities é maligna à manutenção da inflação dentro da meta.

Em 2010 e no início de 2011 fenômenos climáticos extremos em diversas partes do mundo afetaram lavouras. Estoques de diversos produtos agrícolas estão baixos. A inelasticidade da oferta de alimentos no curto prazo pressiona as cotações para cima. Do mesmo modo, a crescente liquidez do mercado financeiro internacional, advindo da política monetária americana, induz investidores especuladores a proteger suas economias entrando no mercado futuro e comprando commodities. A demanda chinesa por alimentos é historicamente alta. Diante do recorde de número de habitantes, o aumento da renda dos trabalhadores e o alto nível de crescimento do produto, a China impõe forte pressão à oferta de commodities e consequentemente nos seus preços.

Há ainda o problema adicional da instabilidade política no Norte da África e no Oriente Médio, como exemplo temos a Líbia e o Egito, que tem impulsionado as cotações do petróleo para níveis acima dos 110 dólares o barril, em níveis de pré-crise financeira 2008.

Assim, parte da inflação acumulada no Brasil em 2011 é "importada" porque deriva dos preços altos das commodities agrícolas e minerais no mercado internacional. Pela pressão inflacionária advinda do mercado futuro, subir juros poderá não ter efeito para controlar o IPCA dentro da meta. É simples entender: os preços dos produtos agrícolas na bolsa de Chicago ou do preço do petróleo na bolsa de Londres não irão diminuir porque os juros brasileiros irão aumentar.

Assim, pelo aumento dos preços no mercado futuro, o excesso de demanda agregada só pode produzir uma pressão altista nos preços no mercado à vista $(s p o t)$. Se os preços do mercado à vista são mais elevados que os preços no mercado futuro (forward), um ajuste de quantidades irá ocorrer, de modo a garantir a eliminação da inflação produzida pelo excesso de demanda. Preços no mercado futuro, no entanto, não são influenciados pelas condições de demanda, mas determinado pelo fluxo de oferta dos bens e serviços, que dependem das margens de lucro desejadas pelos empresários e de salário real desejado pelos sindicatos. Isto significa 
que um persistente aumento do nível de preços só pode ocorrer como resultado do conflito distributivo entre salários e lucros. Esta é a visão estruturalista da inflação, a qual determina que a taxa de inflação resulta do conflito entre trabalhadores e capitalistas acerca da distribuição da renda e dos custos de fatores como o preço de matérias-primas e petróleo. Nesta situação, variações das taxas de juros não têm grandes efeitos para controle de inflação.

\section{O ALTO NÍVEL DE EMPREGO NA ECONOMIA BRASILEIRA VERIFICADA NOS ÚLTIMOS MESES}

Conforme o Gráfico 2, a taxa de desemprego aberta no Brasil em dezembro de 2010 foi de 5,3\% e em janeiro, pela sazonalidade, aumentou para 6,1\%, ambos em níveis históricos recordes dentro do regime de metas de inflação.

GRÁFICO 2 - TAXA DE DESEMPREGO ABERTO MENSAL EM \%, 2001-2011

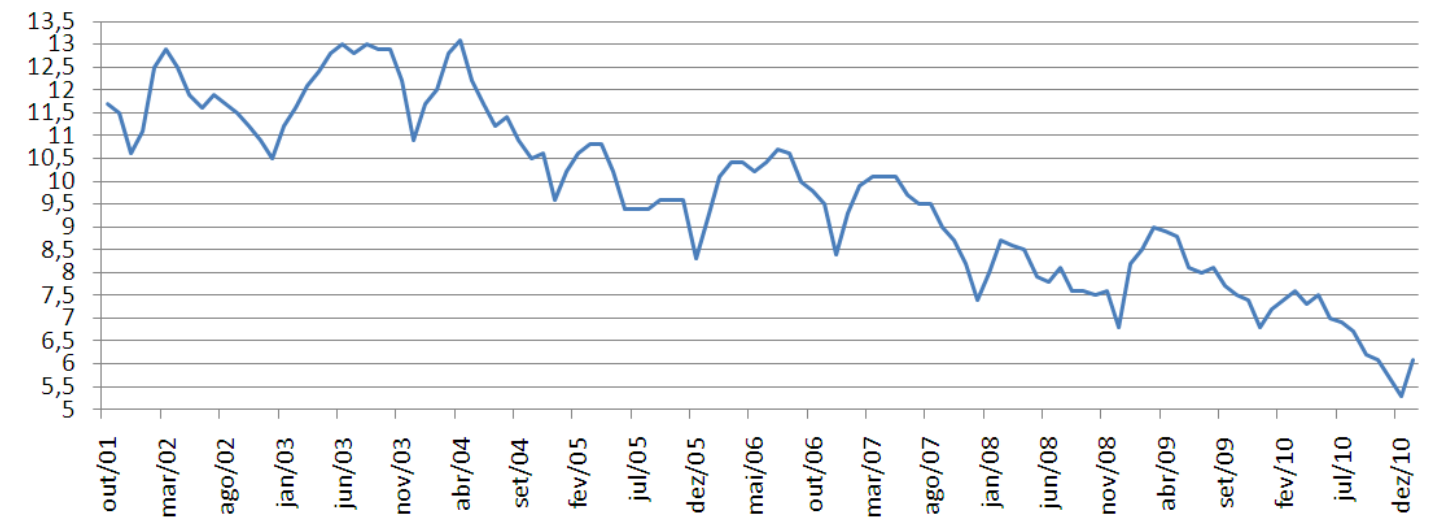

FONTE: IBGE.

Pela segunda pressão inflacionária nomeada, o alto nível de emprego em relação a períodos anteriores dentro do regime de metas de inflação, não é necessário que a economia brasileira esteja operando com "pleno emprego" para observar elevação persistente dos índices inflacionários.

Basta que a taxa de desemprego efetiva esteja abaixo da NAIRU (non-accelerating inflation rate of unemployment). Se esse é o caso prevalecente no Brasil (questão empírica e não teórica), e se o único instrumento de controle inflacionário a disposição do governo é a taxa de juros, então o Banco Central do Brasil deverá continuar a elevar nas próximas reuniões, programadas para abril e junho, a taxa básica de juros no nível suficiente para desaquecer a economia brasileira a ponto de colocar a taxa de desemprego efetivo novamente em linha com a NAIRU. Esta taxa de desemprego inclusive pode estar acima do que observamos hoje. O efeito do aumento dos juros básicos no Brasil para combate à inflação terá efeito positivo se os salários e as margens de 
lucro são sensíveis às variações na taxa de desemprego. Aqui uma política monetária restritiva, com impopulares aumentos das taxas de juros, como o Banco Central do Brasil está fazendo e continuará a fazer nos próximos períodos, pode induzir sindicatos a aceitarem salários menores e/ou induzir empresários a aceitarem margens de lucros menores, reestabelecendo o equilíbrio da distribuição da renda e interrompendo o processo de aceleração da inflação.

\section{A RECENTE EXPANSÃO DE CRÉDITO NO BRASIL}

Conforme o Gráfico 3, a partir de meados de 2004 inicia-se um crescimento gradual e sustentado do crédito, cuja participação no PIB aumenta de 24,0\% em março de 2004 para 46,5\% do PIB em janeiro de 2011.

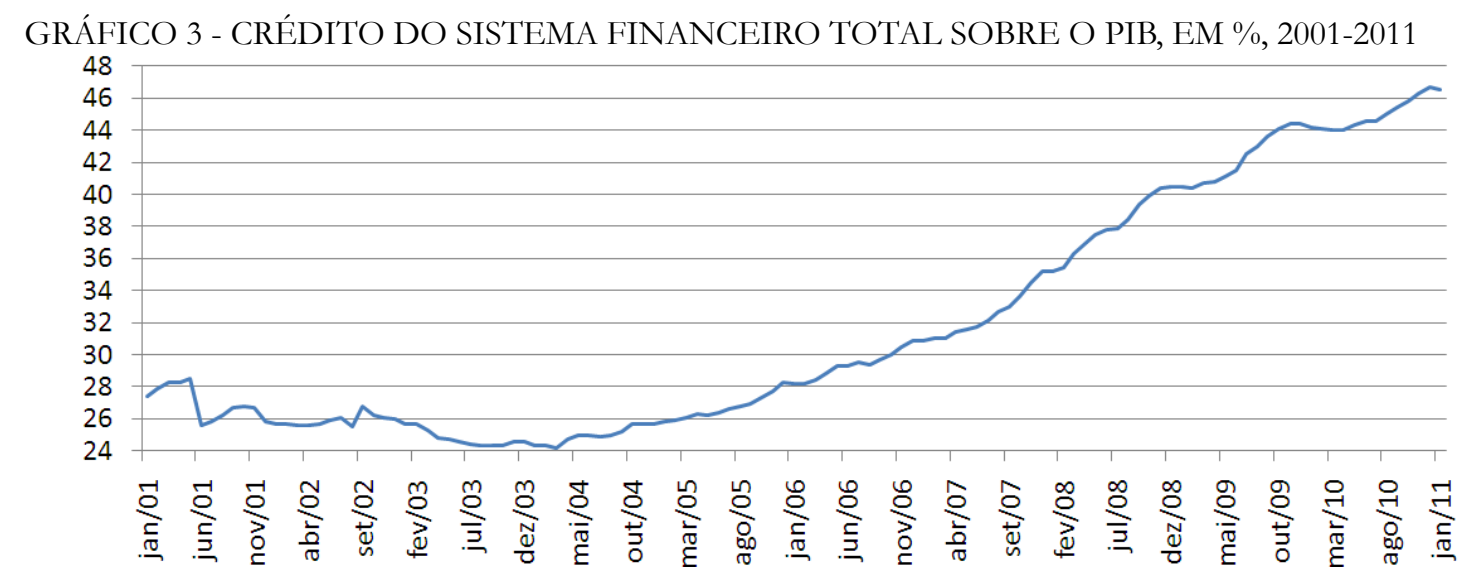

FONTE: Banco Central do Brasil.

Como condicionantes macroeconômicos mais gerais deste crescimento, segundo Correa, Paula, Oreiro e Basílio (2010, p.5): "pode-se apontar o maior crescimento da renda e do produto, certa redução na taxa nominal de juros, a estabilidade macroeconômica (resultando em uma volatilidade menor de variáveis macroeconômicas básicas, como taxa de câmbio e taxa de juros....)".

O aumento da taxa de crescimento do consumo interno pela massa de trabalhadores que saíram da linha da pobreza/miséria nos últimos anos e também da classe média brasileira pelo crédito relativamente farto e relativamente mais barato que períodos anteriores, aliado ao fenômeno de euforia, também podem ser indícios para causar pressão inflacionária neste momento da economia brasileira ${ }^{1}$.

Aqui medidas "prudenciais" de controle de crédito podem amenizar o efeito na pres-

1 Euforia - como existia uma população com demanda reprimida e sem acesso ao consumo, com o aumento da massa de trabalhadores, com os programas de distribuição de renda do governo, queda do desemprego, aliado à expansão do crédito pelas instituições financeiras, as famílias começaram a gastar mais e também pressionar os preços, principalmente da construção civil. 
são inflacionária, vista pelo aumento do IPCA e sua aproximação no teto superior da meta. A primeira mudança, realizada ainda no final de 2010, combinada com o aumento da taxa SELIC, foi o uso de instrumentos de política monetária ditos "não convencionais", como o aumento do depósito compulsório e do requerimento de capital dos bancos para empréstimos de longo prazo como forma de produzir uma redução do ritmo de expansão do crédito, reduzindo o crescimento da demanda agregada e, conseqüentemente, objetivando a redução da inflação IPCA num prazo mais longo (2012/2013, por exemplo) para o centro da meta.

\section{A RECENTE EXPANSÃO MONETÁRIA NOS ESTADOS UNIDOS E EXPORTA- ÇÃO DA INFLAÇÃO}

Um agravante adicional para aceleração da inflação no Brasil é advindo das condutas de política monetária americana, em especial o Quantitative Easing 2. Pela teoria monetária que a injeção de moeda gera vis-à-vis inflação, pode-se afirmar que os Estados Unidos estão exportando seus problemas monetários e consequentemente inflacionários para países emergentes, incluindo o Brasil.

O programa Quantitative Easing 2 do Federal Reserve tem como intenção gerar mais liquidez aos mercados e retirar ainda os títulos podres em excesso. A consequência certa é mais inflação. A valorização mundial de várias moedas (o câmbio supervalorizado de vários países como no Brasil) nada mais é do que uma inflação dos produtos do resto do mundo para os EUA importar. Os produtos do resto do mundo estão ficando mais caros para os norte-americanos.

$\mathrm{Na}$ avaliação da OCDE (nov/2010), os recursos injetados nos países ricos durante os últimos 2 anos, 2009 e 2010, e em especial nos últimos meses deram demonstrações claras de que não estão sendo escoados nas economias locais que injetaram tais recursos, no caso Europa e Estados Unidos (indicadores de política monetária e crédito). Parte substancial dessa massa de dinheiro injetado nas economias desenvolvidas teriam se destinado para as economias emergentes pelo risco-país melhorado em relação aos Estados Unidos e taxas de câmbio com expectativas de depreciação do dólar.

Como o governo americano tende a manter os juros, tanto de curto e longo prazo, a taxas historicamente baixas, por diversas teorias monetárias existentes, dentro de um mundo agora conectado e globalizado, existirá a continuidade da pressão inflacionária nos países emergentes, dado as taxas de juros que estes países estão praticando.

Portanto, aqui o Banco Central do Brasil teria que, mais uma vez, adotar novas medidas de aumentos da taxa de juros e controle de créditos, além daquelas anunciadas nos últimos 
três meses, de maneira mais incisiva, aliados a políticas de controle de capitais para tentar anular o efeito da política monetária sobre o câmbio, ou seja, combater a inflação e ao mesmo tempo fazer com que a moeda nacional não se aprecie ainda mais pelos ganhos de arbitragem dos juros (apesar que a apreciação desacelera a inflação) para que não exista desindustrialização e falta de manutenção do atual nível de emprego da economia brasileira.

\section{REFERÊNCIAS}

BANCO CENTRAL DO BRASIL. Boletim FOCUS. Disponível em: < http://www4.bcb. gov.br/pec/GCI/PORT/readout/R20110211.pdf>.

CORREA, P. R.; PAULA, L. F.; OREIRO, J. L. C.; BASÍLIO, F. A. C. A estrutura do setor bancário brasileiro e o ciclo recente de expansão do crédito: o papel dos bancos públicos. ANPEC, 2010.

OCDE. Changing for the better: Making reform happen in the aftermath of the crisis. Disponível em: <http://www.oecd.org/document/5/0,3746,en_21571361_44315 115 _46535173_ 1_1_1_1,00.html>.

OREIRO, J. L.C. Inflação, política monetária e o problema do juro no Brasil. Disponível em: <http://www.cartamaior.com.br/templates/materiaMostrar.cfm?materia_id=17530>. Acesso em: 10/03/2011. 
